\title{
The association of iron deficiency anaemia with simple febrile seizures in children less than 5 years age: A single centre, prospective, case-control study
}

\author{
Dipak Madavi ${ }^{1}$, *Bharath Kumar $\mathbf{S}^{1}$, Nidhi Nashine ${ }^{1}$
}

Sri Lanka Journal of Child Health, 2021; 50(1): 75-82

\begin{abstract}
Introduction: Febrile seizure (FS) has an incidence of $2-5 \%$ in the neurologically healthy child. Among various risk factors, iron deficiency anaemia (IDA) is implicated in the increased risk of FS.
\end{abstract}

Objectives: To primarily assess the association between IDA and simple FS and secondarily the association of other risk factors with simple FS.

Method: This was a single centre, prospective, case control study involving 120 children, aged between 6 months and 5 years, 60 presenting with simple FS (cases) and 60 presenting with acute febrile episodes without seizures (controls). The study was performed from September 2017 to August 2019. Cases and controls were matched for age, sex, weight, and height. Laboratory investigations such as complete blood count, serum iron (SI), total iron binding capacity (TIBC), and SI/TIBC index were performed and compared between the two groups.

Results: Compared to controls, significantly higher number of cases had a family history of FS and family history of seizure disorder (both $p$ values $<0.05$ ). Moreover, as compared to controls, cases had significantly lower median haemoglobin levels, mean corpuscular volume, mean corpuscular haemoglobin, and mean corpuscular haemoglobin concentration (all p-values $<0.05$ ). However, cases had significantly higher median red cell distribution width ( $p$-value $=0.004)$. Similarly, cases had a significantly lower mean SI levels, and SI/TIBC index, as compared to controls (both pvalues $<0.05)$. However, cases had significantly higher mean TIBC ( $p$-values $<0.05)$. Finally, as

${ }^{1}$ Indira Gandhi Government Medical College, Nagpur, India

*Correspondence: bharathbilla5@gmail.com

https://orcid.org/0000-0001-6910-2337

(Received on 01 March 2020: Accepted after revision on 24 April 2020)

The authors declare that there are no conflicts of interest

Personal funding was used for the project.

Open Access Article published under the Creative

Commons Attribution CC-BY (C) (i) License compared to the controls, cases with IDA had 8.4 fold increased risk of developing the FS.

Conclusions: The findings of this study suggest that IDA is a risk factor for the development of FS in children aged $<5$ years.

DOI: http://dx.doi.org/10.4038/sljch.v50i1.9406

(Key words: Anaemia, children, febrile seizures, iron deficiency, serum iron, total iron binding capacity)

\section{Introduction}

Febrile seizure (FS) has an incidence of $2-5 \%$ in the neurologically healthy child ${ }^{1-3}$. It is particularly prevalent amongst the Asian population and has a predilection for male $\operatorname{sex}^{4}$. The exact aetiology of FS remains unknown. Some studies have demonstrated a strong family history of FS in siblings and parents, suggesting a genetic predisposition, while other studies have implicated environmental factors in its causation ${ }^{5}$. Thus, multiple risk factors have been suggested to result in $\mathrm{FS}^{4}$. Amongst children, the maximum incidence of iron deficiency anemia (IDA) is reported to be in the 6 months to 2 year age group and this coincides with the FS peak incidence age group ${ }^{6}$. However, research studies have conflicting reports explaining the link between FS and IDA amongst children ${ }^{7-9}$. In these studies, a few authors have concluded that iron deprivation plays a role in the pathogenesis of FS, while others disproved the causative role of IDA in FS. Studies have reported a higher prevalence of IDA and FS in Central India ${ }^{8}$. However, the association between them has not been studied.

\section{Objectives}

To primarily assess the association between IDA and simple FS and secondarily the association of other risk factors such as family history of FS and family history of seizure disorders with simple FS.

\section{Method}

A prospective, single centre, case-control study, involving 120 subjects (60 cases and 60 controls) visiting the Out-patient Department (OPD) and admitted in the wards of Paediatric Department, Indira Gandhi Government Medical College and 
Hospital, Nagpur, was conducted from September 2017 to August 2019.

\section{Eligibility criteria}

Cases of either sex, 6 months to 5 years old, presenting with simple FS, were included in the study. Similarly, controls were enrolled except that they presented with acute febrile illness (AFI) without seizures (AFI $>24$ hours, up to 48 hours without any CNS involvement). However, cases and controls with neurological infections, delayed development, those already on iron therapy, and previously diagnosed anaemia of other causes were excluded. Additionally, controls with past history of febrile seizures and seizure disorders were excluded. Screening investigations were carried out and the eligible candidates were included in the study.

\section{Procedure}

After admission, information related to age, gender, height, weight, and family history of FS and family history of seizure disorder were obtained from both cases and controls, while, information related to the family history of seizure disorder was noted only in the cases. The data were then entered into a predesigned structured case record form. All the subjects received an appropriate diet (including iron-rich food such as groundnuts, jaggery, greenleafy vegetables, and non-vegetarian diet) for their ages and were free of any feeding-related problems such as limited appetite; resistance to feeding; partial or total refusal of foods according to its texture, colour, smell, consistency, or taste; and organic causes including food allergy, coeliac disease, oesophagitis, gastro-oesophageal reflux, and others. Both cases and controls were matched for age, sex, height, and weight.

The cases were diagnosed as having simple FS, if the seizure was primary generalized, usually tonicclonic, associated with fever $\left(\geq 38{ }^{\circ} \mathrm{C}\right)$, remained for not more than 15 minutes, and did not recur within a period of 24 hours $^{10}$. The general examination included the measurement of height and weight of the subjects. For children 2 years and below, infantometer was used and stadiometer was used for the children aged $>2$ years. The portable digital weighing machines (different machines for children 2 years and below and $>2$ years) were used to weigh the children.

\section{Laboratory investigations}

Investigations on admission included complete blood count $(\mathrm{CBC})$, serum iron (SI), total iron binding capacity (TIBC), and SI: TIBC ratio. Clinical evaluation was performed to rule out other causes of anaemia.

In 6 month to 5 year old children, the normal level of SI and SI: TIBC ratio were $60-170 \mu \mathrm{g} / \mathrm{dl}(10-$ $30 \mu \mathrm{mol} / \mathrm{L}$ ) and $20-50 \%$, respectively. The normal range of TIBC in infants was 100-400 $\mu \mathrm{g} / \mathrm{dl}$, and thereafter, 250-400 $\mu \mathrm{g} / \mathrm{dl}^{10,11}$. All blood counts were calculated by Sysmex XS-800i CBC machine
(Norderstedt Germany) and serum iron and TIBC were calculated by Biochemical Systems International SpA - 3000 Evolution (Arezzo (AR) Italia).

Anaemia was defined as a $\mathrm{Hb}$ level $<11 \mathrm{~g} / \mathrm{dL}$. Iron deficiency was defined as SI $<40 \mu \mathrm{g} / \mathrm{dL}$ (for subjects $<1$ year of age) and $<50 \mu \mathrm{g} / \mathrm{dL}$ (for subjects 2-5 year of age), or transferrin saturation $<16 \%{ }^{12}$

\section{Sample size calculation}

Anticipated probabilities of IDA in cases (P1) was 0.22 and odds ratio (OR) was $3.16 .^{13}$

The P2 was calculated by the formula:

$\mathrm{P} 2=\frac{P 1}{O R(1-P 1)+P 1}$

Value of normal deviation at $5 \%$ confidence interval $(Z 1-\alpha)$ and $80 \%$ power of the study $(Z 1-\beta)$ were considered to be 1.64 and 0.842 , respectively. Thus, the final sample size was calculated based on the formula:

$\mathrm{N}=\frac{[Z 1-\alpha \sqrt{2 P 2(1-P 2)}+Z 1-\beta \sqrt{P 1(1-P 1)+P 2(1-P 2)}]^{2}}{(P 1-P 2)^{2}}$ $=60$. Thus, the sample was found to be 120 , with 60 subjects in cases group and 60 subjects in control group.

Ethical issues: Ethical clearance was obtained from the Ethics Committee of Indira Gandhi Government Medical College and Hospital, Nagpur, India. After explaining the study procedures, an assent from the subjects and written informed consent from the parents was obtained

\section{Statistical analysis}

Qualitative variables are expressed as frequencies $(\%)$ and continuous variables as mean $( \pm \mathrm{SD})$ or median (interquartile range). Various haematological parameters were compared between cases and controls. After checking normality of the data by Shapiro-Wilk test, we performed MannWhitney $U$ tests for non-normally distributed data and independent t-tests for normally distributed data. A Chi-square test was performed to compare qualitative variables, between case and control. A two-tailed probability (p) value of less than 0.05 was considered as statistically significant. Data analysis was performed with the help of Statistical Package for Social Sciences Software, version 23.0 (SPSS, IBM Inc, Chicago, Illinois, USA).

\section{Results}

Majority of children in both groups were males i.e. cases $(58.3 \%)$ and controls $(65 \%)$. Most of the subjects in both groups belonged to 0.5 to 2 years of age i.e., cases $(63.3 \%)$ and controls (66.7\%). Moreover, there was no significant difference between subjects in terms of distribution in various age groups i.e., $0.5-2$ years $(\mathrm{p}=0.702), 2.1-4$ years $(\mathrm{p}=0.841)$, and $4.1-5$ years $(\mathrm{p}=0.697)$. Finally, there was no significant difference between 
subjects in both groups in terms of $\operatorname{sex}(p=0.453)$, median age $(\mathrm{p}=0.675)$, weight $(\mathrm{p}=0.104)$, and height $(\mathrm{p}=0.912)$. Thus, the cases and controls were matched in terms of sex, age, weight, and height (Table 1).

Table 1: Matching of cases and controls (according to gender, age, weight, and height)

\begin{tabular}{|l|c|c|c|}
\hline & Cases & Controls & p-value \\
\cline { 1 - 3 } Male n (\%) & $35(58.33)$ & $39(65)$ & \multirow{2}{*}{$0.453^{\#}$} \\
\hline Female n (\%) & $25(41.67)$ & $21(35)$ & $0.675^{*}$ \\
\hline Age in years Median (IQR) & $2(1-4)$ & $2(1-3)$ & $0.104^{*}$ \\
\hline Weight in kg Median (IQR) & $10(8.35-12.00)$ & $8.5(7.8-11.88)$ & $0.912^{*}$ \\
\hline Height in cm Median (IQR) & $82(72.50-89.50)$ & $83(73.00-92.75)$ & \\
\cline { 1 - 3 }
\end{tabular}

Non-parametric variables presented as frequency (percentages); Skewed variables presented as median (interquartile range); \# Chi-square test; *Mann-Whitney U test; p-value $<0.05$ was considered as statistically significant

It was observed that pallor $(\mathrm{p}<0.0001)$, pica $(p<0.0001)$, and platynychia $(p<0.0001)$ were more prevalent amongst cases than controls. Moreover, as compared to controls, cases had significantly higher number of subjects with family history of FS $(p<0.0001)$. Similarly, cases had significantly higher number of subjects with family history of seizure disorder, as compared to controls ( $p=$ 0.012) (Table 2).

Table 2: Distribution of study groups according to clinical features, family history \& past history of seizures

\begin{tabular}{|c|c|c|c|}
\hline Clinical features & $\begin{array}{c}\text { Cases }(n=60) \\
n(\%)\end{array}$ & $\begin{array}{c}\text { Controls }(n=60) \\
n(\%)\end{array}$ & p-value \\
\hline Pallor & $38(63.3)$ & $16(26.7)$ & $<0.0001^{*}$ \\
\hline Pica & $43(71.7)$ & $21(35.0)$ & $<0.0001^{*}$ \\
\hline Platynychia & $15(25.0)$ & $01(01.7)$ & $<0.0001^{*}$ \\
\hline \multicolumn{4}{|c|}{ Family history of febrile seizures } \\
\hline Yes & $13(21.7)$ & $0(0)$ & \multirow[t]{2}{*}{$<0.0001$} \\
\hline No & $47(78.3)$ & $60(100)$ & \\
\hline \multicolumn{4}{|c|}{ Family history of seizure disorder } \\
\hline Yes & $13(21.7)$ & $0(0)$ & \multirow[t]{2}{*}{0.012} \\
\hline No & $47(78.3)$ & $60(100)$ & \\
\hline
\end{tabular}

Non-parametric variables presented as frequency (percentages); ${ }^{*}$ Chi-square test; p-value $<0.05$ was considered as statistically significant

On $\mathrm{CBC}$ analysis, there were significantly higher number of cases with anaemia i.e. $\mathrm{Hb}<11 \mathrm{~g} \%$, as compared to controls (35 vs 13; $\mathrm{p}<0.0001)$. Moreover, as compared to controls, significantly higher number of cases had $\mathrm{Hb}$ levels in the range of $6-8 \mathrm{~g} \%(\mathrm{p}=0.013)$ and $8-11 \mathrm{~g} \%(\mathrm{p}=0.007)$. On further analysis, it was observed that median $\mathrm{Hb}$ levels ( $p<0.0001)$, median MCV ( $\mathrm{p}=0.006)$, median $\mathrm{MCH}(\mathrm{p}<0.0001)$, and median MCHC $(\mathrm{p}$ $<0.0001)$ were significantly lower amongst cases than controls. However, as compared to controls, cases had significantly higher median RDW ( $\mathrm{p}=$ 0.004) (Table 3).

Table 3: Comparison of cases and controls according to severity of anaemia and haematological parameters

\begin{tabular}{|l|c|c|c|}
\hline \multicolumn{1}{|c|}{ Severity of anaemia (Hb) } & Cases $(\boldsymbol{n}=35)$ & Controls $(\boldsymbol{n}=\mathbf{1 3})$ & p-value \\
\hline$<6 \mathrm{~g} \%$ & 1 & 1 & $1.000^{*}$ \\
\hline $6-8 \mathrm{~g} \%$ & 12 & 3 & $0.013^{*}$ \\
\hline $8-11 \mathrm{~g} \%$ & 22 & 9 & $0.007^{*}$ \\
\hline CBC parameters & \multicolumn{3}{|c|}{} \\
\hline Hb (g \%) Median (IQR) & $10.05(8.43-11.98)$ & $12.10(11.53-12.80)$ & $<0.0001^{*}$ \\
\hline MCV (fl) Median (IQR) & $69.25(62.90-77.25)$ & $74.35(72.55-77.33)$ & $0.006^{*}$ \\
\hline MCH (pg/cell) Median (IQR) & $22.10(19.30-25.40)$ & $26.18(24.10-28.08)$ & $<0.0001^{*}$ \\
\hline MCHC (g/dl) Median (IQR) & $30.75(26.33-33.10)$ & $34.80(32.13-36.95)$ & $<0.0001^{*}$ \\
\hline RDW (\%) Median (IQR) & $18.00(12.63-21.88)$ & $13.10(12.33-15.08)$ & $0.004^{*}$ \\
\hline
\end{tabular}

Non-parametric variables presented as frequency (percentages); ${ }^{*}$ Chi-square test; p-value $<0.05$ was considered as statistically significant. 
On evaluating the SI and TIBC, cases were found to have a significantly lower mean SI levels ( $\mathrm{p}=$ $0.044)$, and lower median SI/TIBC index ( $\mathrm{p}=$ $0.004)$ than controls. However, as compared to controls, cases had significantly higher mean TIBC $(\mathrm{p}=0.006)($ Table 4$)$.

Moreover, significantly higher number of cases had SI and SI/TIBC index less than the reference values, as compared to controls (26 vs 5; $\mathrm{p}=0.021)$ (Table 5).

Finally, it was observed that the presence of IDA resulted in 8.4 fold increased risk of developing FS (Table 6).

Table 4: Distribution of cases and controls according to the parameters of iron deficiency anaemia

\begin{tabular}{|l|c|c|c|}
\hline Parameters & Cases $[\mathbf{N}=\mathbf{3 5}]$ & Controls [N = 13] & p-value \\
\hline SI $(\mu \mathrm{g} / \mathrm{dl})$ & $45.01 \pm 9.85$ & $51.21 \pm 7.05$ & $0.044^{\#}$ \\
\hline TIBC $(\mu \mathrm{g} / \mathrm{dl})$ & $444.72 \pm 96.90$ & $355.01 \pm 95.90$ & $0.006^{\#}$ \\
\hline SI/TIBC Index $(\%)$ & $9.72(7.55-16.13)$ & $16.21(14.49-16.73)$ & $0.004^{*}$ \\
\hline
\end{tabular}

SI: Serum iron; TIBC: Total iron binding capacity; Variables with a normal distribution are represented as mean $\pm S D$; Skewed variables presented as median (interquartile range); *Mann-Whitney U test; \#Unpaired ttest; $p$-value $<0.05$ was considered as statistically significant.

Table 5: Distribution of cases and controls according to the confirmation of iron deficiency anaemia

\begin{tabular}{|l|c|c|c|c|}
\hline \multicolumn{1}{|c|}{ Parameters } & Criteria & Cases $[\mathbf{N}=\mathbf{3 5}]$ & Controls [N = 13] & p-value \\
\hline SI $(\mu \mathrm{g} / \mathrm{dl})$ & $<1$ year: 40 & 2 & 0 & $0.021^{*}$ \\
\hline & $>1$ year: 50 & 24 & 5 & $0.021^{*}$ \\
\hline SI/TIBC Index $(\%)$ & $<16$ & 26 & 5 & $0.021^{*}$ \\
\hline Total & & 26 & 5 & $<$ \\
\hline
\end{tabular}

Non-parametric variables presented as frequency (percentages); ${ }^{*}$ Chi-square test; p-value $<0.05$ was considered as statistically significant.

Table 6: Risk estimate for iron deficiency anaemia and febrile seizures

\begin{tabular}{|c|c|c|c|}
\hline Variable & Odd's ratio & $\mathbf{9 5 \%}$ CI & p-value \\
\hline IDA [Cases $(\mathrm{N}=26)$ versus Controls $(\mathrm{N}=5)]$ & 8.412 & $2.949,23.996$ & $<0.0001$ \\
\hline
\end{tabular}

IDA: iron deficiency anaemia; CI: Confidence interval; p-value <0.05 was considered as statistically significant

\section{Discussion}

Amongst all the micronutrient deficiencies, iron deficiency is the commonest in the paediatric age group. More importantly, it can be easily corrected and treated. Still, it is observed that, in developing countries, around $46-66 \%$ of under-fives children are anaemic. This condition is much worse in India and the $3^{\text {rd }}$ National Family Health Survey (NFHS3 ) reported that $70 \%$ of under-five children are anaemic $^{6,14}$. IDA is linked to neurological symptoms such as irritability, breath holding spells, impaired cognition, poor school performance, and delay in language development. Additionally, it is also linked to certain morbid conditions such as FS, ischaemic strokes, and pseudo tumour cerebri. Though the role of iron in these conditions is still unclear, some of the contributing factors include abnormal synthesis and metabolism of neurotransmitter, improper myelin formation, and impaired brain energy metabolism. Thus, it is thought iron deficiency may result in change in seizure threshold thus precipitating in the seizures ${ }^{8}$.

Principal findings of this study are that $43.3 \%$ of the subjects with FS had IDA and as compared to controls, the presence of IDA results in 8.4 times increased chances of FS. However, uncertainty still persist over the role of IDA in FS, with various studies reporting contradictory findings. Findings of this study are supported by Kumar et al, who reported higher susceptibility to FS in the cases with iron deficiency ${ }^{7}$. Similar findings are reported by two other different studies ${ }^{6,15}$. In the first study, Sharif et al evaluated the relationship between iron deficiency and FS and suggested that a considerable percentage of children with FS had IDA and low $\mathrm{SI}^{15}$. In the second study, Chandrashekar et al. reported that IDA was found more commonly amongst children with FS as compared to those with febrile illness alone ${ }^{6}$. However, observations of other studies refute the findings of this study. A study by Waheed et al. reported that iron concentration is not linked to the development of $\mathrm{FS}^{16}$. In another study, Kamalammal et al. evaluated the association between IDA and FS in children aged 3 to 60 months and observed that there are no significant differences and rejected the claim that IDA is a triggering factor for $\mathrm{FS}^{17}$. Similarly, Bharat et al. failed to establish any link between IDA and $\mathrm{FS}^{8}$. Kobrinsky et al. suggested that iron deficiency may even prevent the development of $\mathrm{FS}^{18}$. Following 
these conflicting results, recent meta-analysis by Kwak et al., reported a clear association between IDA and FS, with an OR of 2.08 to $3.78^{19}$. Similarly, Nasehi et al. had reported an increased incidence of FS in children with IDA $(\mathrm{OR}=1.27$, $95 \%$ CI $=1.03-1.56)^{20}$. Similar to this study, Aziz et $a l^{21}$ and Jang et $a l^{22}$ performed case control studies in which cases and control were matched for age and gender. However, the latter study reported that the majority of the patients were female. Moreover, as per Leung et al. the male-tofemale ratio in FS seizures is approximately 1.6 to $1^{4}$. This is similar to the male-to-female ratio amongst the cases enrolled in this study i.e., 1.4 to 1.

The findings of this study in terms of presenting features (i.e., pallor, pica, and platynychia) are similar to those mentioned in the literature. Kumar et al. observed pallor to be the most common sign in children (94\%) with IDA. However, platynychia was present in only $5 \%$ of the children ${ }^{23}$. Similarly, Soudhabi et al. observed that $50 \%$ of the children of an orphanage had pallor and 34\% had nail changes in the form of platynychia and koilonychias $^{24}$. Studies conducted by Shruti et al ${ }^{25}$ and Gupta et $a l^{26}$ also reported a statistically significant association between pica and IDA $(\mathrm{p}<$ $0.5)$. However, Sadeghzadeh et al. did not find any association between pica and anaemia and/or iron deficiency $(p>0.05)^{27}$. This might be because pica is more a cultural behaviour than a result of iron deficiency.

In accordance with Fallah et $a l^{28}$ and Kumar et $a l^{29}$ this study reported a positive family history of FS in cases, however in the study performed Fallah et $a l$. this did not reach statistical significance ${ }^{28}$. All studies suggests that family history of seizures could be one strong predisposing factor ${ }^{30,31}$. We could not find any study assessing the role of family history of seizure disorder in patients of FS. However, finding of this study suggest a significant association between the two $(\mathrm{p}=0.012)$.

This study observed a significant association between the severity of anaemia and FS $(\mathrm{p}<0.0001)$. Similarly, Ghosal S, et al. observed that significantly greater number of cases with FS had moderate to severe grade of anaemia $(p<0.001)$. Moreover, children with moderate to severe anaemia were 6 times more likely to develop FS $(\mathrm{p}<0.001) .{ }^{32}$ Similarly, Pisacane et al. reported that compared to controls, children with hemoglobin $<10 \mathrm{~g} \%$ had 2.6 times higher risk of developing $\mathrm{FS}^{33}$. Thus, severity of the anemia is a risk factor for developing febrile seizures. In this study, compared to controls, cases had significantly lower median $\mathrm{Hb}, \mathrm{MCV}, \mathrm{MCH}$, and $\mathrm{MCHC}$, but higher median RDW. Similarly, Aziz et al. reported significant difference between cases and controls in terms of mean Hb levels $(\mathrm{p}=0.001)$ and RDW ( $\mathrm{p}=$ $0.004)^{21}$. In another study, Srinivasa et al. reported low $\mathrm{Hb}, \mathrm{MCV}$, and MCHC in febrile fits cases as compared to control (Odd ratio 1.84) $)^{34}$. Additionally, Sharawat et al. observed that RBC indices showed statistically significant lower mean $\mathrm{Hb}, \mathrm{MCV}$, and $\mathrm{MCH}$ and higher RDW values in cases compared to controls ${ }^{35}$. However, contrary to the findings of this study, Jang et al., observed no significant difference between the groups in terms of CBC parameters (all p-values $>0.05)^{22}$. This could be due to low prevalence of IDA and improved nutritional status amongst South Korean children. The findings of this study are in accordance with Jang et al. who observed a significantly increased TIBC and significantly lower SI levels in cases, as compared to controls ${ }^{22}$. Sharif et al. observed a significant difference between cases and controls in the mean SI (p-value $=0.028)$ and TIBC $(p=0.0001)$. Additionally, the presence of IDA was significantly greater amongst the cases than the controls $(45 \%$ vs $22 \%$; p = $0.0005)^{15}$. Additionally, Sadeghzadeh et al. observed that SI: TIBC index $<12 \%$ was found in $58 \%$ of the cases which was significantly higher than the controls $(\mathrm{p}=0.000035)^{36}$. Thus, the findings of this study are similar to those cited in the literature. Since iron deficiency is implicated in the development of FS, its early diagnosis and introduction of iron supplements can help reduce the incidence of FS. Thus, iron status should be routinely checked in children presenting with FS or who are at risk of developing FS.

\section{Conclusions}

Children with FS (cases) had lower levels of haematologic parameters such as $\mathrm{Hb}, \mathrm{MCV}, \mathrm{MCH}$, and MCHC. A family history of FS and a family history of seizure disorders are both risk factors for developing FS in children. Additionally, these children have decreased SI and SI: TIBC index; thus, suggesting an association between FS and IDA. Finally, we conclude that IDA is associated with an increased risk of FS.

\section{Acknowledgement}

The authors would like to thank Dr. Vikas $S$. Sharma, $M D$, an independent medical writer, for medical writing support and editorial assistance in the preparation of this article.

\section{References}

1. Johnston MV. Seizures in childhood. In: Kleigman RM, Behrman RE, Jenson HB, Stanton BP, editors. Nelson text book of pediatrics. 18th ed. Philadelphia: Saunders Elsevier; 2007. P. 2457-8. 
2. Mikati MA. Seizures in childhood. Kliegman RM, Stanton BF, Schor NF, St. Geme JW, Behrman RE, editors. Nelson textbook of pediatrics. 19th ed. Philadelphia: Saunders; 2011. P. 2013-7.

3. Esmaeili M, Ghane F, Asadi N, Esmaeili M. Frequency of urinary tract infection in children with febrile convulsion. Medical Journal of Mashhad University of Medical Sciences 2015; 58(2):106-11.

4. Leung AK, Hon KL, Leung TN. Febrile seizures: an overview. Drugs in Context 2018; 7:212536.

https://doi.org/10.7573/dic.212536

PMid: 30038660 PMCid: PMC6052913

5. Vestergaard M, Basso O, Henriksen TB, Ostergaaed J, Olsen J. Febrile convulsions and sudden infant death syndrome. Archives of Disease in Childhood 2002; 86(2):125-7.

https://doi.org/10.1136/adc.86.2.125

PMid: 11827907 PMCid: PMC1761080

6. Chandrasekhar RV, Bhushan SG, Lakshmi VB. Iron deficiency as a risk factor for febrile seizures. International Journal of Pediatric Research 2016; 3(4):269-73. https://doi.org/10.17511/ijpr.2016.104.12

7. Kumar MS, Sasikumar BR. Low iron status: a possible risk factor for febrile seizures. Journal of Evolution of Medical and Dental Sciences 2015; 4(90):15546-8. https://doi.org/10.14260/jemds/2015/2228

8. Bharat K, Yadav RK, Kumar D, Yadav A, Sharan R, Chaturvedi V. Association between iron deficiency anemia and febrile seizures. Pediatric Review: International Journal of Pediatric Research 2015; 2(4):69-74.

https://doi.org/10.17511/ijpr.2015.104.02

9. Hartfield DS, Tan J, Yager JY, Rosychuk $\mathrm{RJ}$, Spady D, Haines $\mathrm{C}$, et al. The association between iron deficiency and febrile seizures in childhood. Clinical Pediatrics (Phila) 2009; 48(4):420-6. https://doi.org/10.1177/000992280933180 0

PMid: 19229063

10. Mikati MA, Tchapyjnikov D. Febrile Seizures. Chapter 611.1. Editors Kliegman RM, St Geme JW, Blum NJ. Nelson
Textbook of Pediatrics, Volume 2, Edition 21; Elsevier, Philadelphia. 2020:717-24.

11. National family health survey (NFHS - 4), 2015-16. International Institute for Population Sciences. Ministry of Health and Family Welfare, Government of India. Available online at: https://dhsprogram.com/pubs/pdf/FR339/F R339.pdf [Last accessed on 10th October 2019]

12. Heeney MM. Iron Deficiency. Chapter 431. Editors Rudolph CD, Rudolph AM, Lister GE, First LR, Gershon AA. Rudolph's Pediatrics. Edition 22; McGraw Hill, New Delhi 2018:1546-8.

13. Fallah R, Tirandazi B, Karbasi SA, Golestan M. Iron deficiency and iron deficiency anaemia in children with febrile seizure. Iranian Journal of Pediatric Hematology and Oncology 2013; 3(1):200-3.

14. World Health Organization. Iron Deficiency Anemia. Assessment, Prevention and Control. A Guide for Program Managers. WHO/NHD/013; Geneva: 2001.

15. Sharif MR, Kheirkhah D, Madani M, Kashani HH. The Relationship between Iron Deficiency and Febrile Convulsion: A Case-Control Study. Global Journal of Health Science 2016; 8(2):185-9. https://doi.org/10.5539/gjhs.v8n2p185

16. Waheed N, Butt MA. Iron status: is there a role in febrile seizures? Journal of Ayub Medical College Abbottabad 2012; 24(34):128-30.

17. Kamalammal R, Balaji MD. Association between iron deficiency anaemia and various red cell parameters with febrile convulsions in children of age group 3 to 60 months. International Journal of Contemporary Pediatrics 2016; 3(2):55962. https://doi.org/10.18203/23493291.ijcp201 61038

18. Kobrinsky NL, Yager JY, Cheang MS, Yatscoff RW, Tenenbein M. Does iron deficiency raise the seizure threshold? Journal of Child Neurology 1995; 10:1059. 
https://doi.org/10.1177/088307389501000 207

PMid: 7782598

19. Kwak BO, Kim K, Kim SN, Lee R. Relationship between iron deficiency anemia and febrile seizures in children: a systematic review and meta-analysis. Seizure 2017; 52:27-34. https://doi.org/10.1016/j.seizure.2017.09.0 09

PMid: 28957722

20. Nasehi MM, Abbaskhanian A, Salehi Omran MR. Association between iron deficiency anemia and febrile seizure: a systematic review and meta-analysis. Journal of Pediatric Review 2013; 1:13-8.

21. Aziz KT, Ahmed N, Nagi AG. Iron deficiency anaemia as risk factor for simple febrile seizures: a case control study. Journal of Ayub Medical College Abbottabad 2017; 29(2):316-9.

22. Jang HN, Yoon HS, Lee EH. Prospective case control study of iron deficiency and the risk of febrile seizures in children in South Korea. BMC Pediatrics 2019; 19:309. https://doi.org/10.1186/s12887-019-16754

PMid: 31484495 PMCid: PMC6724315

23. AshokKumar C, Singla, Nigavekar, Tayade MC, Idgampalli N. Incidence of thrombocytosis in iron deficiency anaemia in paediatric age group in rural population. Indian Journal of Basic and Applied Medical Research 2013; 3(1):45-9.

24. Soudhabi KSH, Bhat B, Anees S, Bangera S. Assessment of nutritional status in children of an orphanage. Indian Journal of Clinical Anatomy and Physiology 2017; 4(2):156-9.

25. Shruti S, Bhatia MS, Rusia U, Rusia A. Iron profile estimation in children of behavioural disorders. Delhi Psychiatry Journal 2010; 13(2):339-40.

26. Gupta N, Sood S. The serum level of iron, zinc, calcium and selenium in children with pica. International Journal of Basic \& Applied Physiology 2014; 3(1):151-15.

27. Sadeghzadeh M, Khoshnevisasl P, Sadeghzadeh S. The relation between pica and iron deficiency in children in Zanjan,
Islamic Republic of Iran: a case-control study. Eastern Mediterranean Health Journal 2017; 23(6): https://doi.org/10.26719/2017.23.6.404 PMid: 28836652

28. Fallah R, Tirandazi B, Ferdosian F, Fadavi $\mathrm{N}$. Iron deficiency and iron deficiency anaemia in children with first attack of seizure and on healthy control group: A comparative study. Iranian Journal of Child Neurology 2014; 8(3):18-23.

29. Kumar B, Thandapani K, Babu V. Iron deficiency anaemia as a risk factor for simple febrile seizures in paediatric patients. International Journal of Contemporary Pediatrics 2019; 6(4): 1414-20.

https://doi.org/10.18203/23493291.ijcp201 92126

30. Kumari LP, Nair MK, Nair SM, Kailas L, Geetha S. Iron deficiency as a risk factor for simple febrile seizures-A case control study. Indian Pediatrics 2012; 49(1):17-9. https://doi.org/10.1007/s13312-012-00086

PMid: 21719928

31. Daoud AS, Batieha A, Abu-Ekteish F, Gharaibeh N, Ajlouni S, Hijazi S. Iron status: A possible risk factor for the first febrile seizure. Epilepsia 2002; 43(7):7403.

https://doi.org/10.1046/j.15281157.2002.3 2501.x

PMid: 12102677

32. Ghosal S. Relationship of iron deficiency anaemia with simple febrile seizure in children. Journal of Bangladesh College of Physicians and Surgeons 2017; 35:759. https://doi.org/10.3329/jbcps.v35i2.33367

33. Pisacane A, Sansone R, Impagliazzo N, Coppola A, Rolando P, D'Apuzzo A, et al. Iron deficiency anaemia and febrile convulsions: case-control study in children under 2 years. British Medical Journal 1996; 313:343. https://doi.org/10.1136/bmj.313.7053.343 PMid: 8760744 PMCid: PMC2351736

34. Srinivasa S, Reddy SP. Iron deficiency anaemia in children with simple febrile seizures-A cohort study. Current Pediatric Research 2014; 18(2):95-8. 
35. Sharawat IK, Singh J, Dawman L, Singh A. Evaluation of risk factors associated with first episode febrile seizure. Journal of Clinical and Diagnostic Research 2016; 10(5):SC10-13.

36. Sadeghzadeh M, Khoshnevis Asl P, Mahboubi E. Iron status and febrile seizure- a case control study in children less than 3 years. Iranian Journal of Child

Neurology 2012; 6(4):27-31.

https://doi.org/10.7860/JCDR/2016/18635

.7853

PMid: 27437319 PMCid: PMC4948495 